Orbis Tertius, vol. XXII, n ${ }^{\circ}$ 25, e046, junio 2017. ISSN 1851-7811

Universidad Nacional de La Plata

Facultad de Humanidades y Ciencias de la Educación

Centro de Estudios de Teoría y Crítica Literaria

\title{
Ricardo Piglia, Las tres vanguardias: Saer, Puig, Walsh.
}

Buenos Aires, Eterna Cadencia, 2016, 222 páginas.

\section{Enzo Matías Menestrina}

En el año 1990 Ricardo Piglia dictó un seminario en la Universidad Nacional de Buenos Aires (UBA) titulado Las tres vanguardias. Tal como señala Patricia Somoza en el Prólogo: "Fue el primero de varios y fue un acontecimiento” (p. 11). Las once clases que comprenden el volumen constituyen un vínculo referencial entre los autores vanguardistas nacionales y extranjeros. Piglia toma como figuras centrales a Juan José Saer, Manuel Puig y Rodolfo Walsh. A lo largo de las clases, instala problemáticas teóricas que pueden ser leídas como debates culturales y de diálogo entre los autores. La primera transcripción de estas clases fue realizada a pedido del propio Ricardo Piglia. La edición busca mantenerse fiel al espíritu, ritmo y tono del curso en el que la misma prologuista ha participado. Estas grabaciones, levemente corregidas al ser transcriptas, pueden leerse como puntos de partida de una discusión literaria de gran magnitud en la que dialogan autores de la literatura nacional y extranjera. Los títulos que encabezan cada clase sirven como síntesis y recorrido en cada caso. Ahora bien, ¿por qué Ricardo Piglia eligió estudiar el proceso de la cultura escrita en estos tres autores? En primer lugar porque son figuras literarias de peso en el campo literario argentino, poseedores de prestigio y con un estilo particular en el que cada uno funda un espacio vanguardista dentro del campo histórico-literario. En estos autores es factible analizar las variables de escritura, su identidad nacional y su vinculación con distintos alcances escriturarios.

En la primera clase Piglia expone una aproximación de lo que tratará el seminario y de los objetivos que se pretenden obtener. Bajo una mirada cautelosa indica que la discusión acerca del estado actual de la literatura argentina comprende una serie de problemas que corresponden al tipo de debate cultural y posición cronológica de las obras en la literatura argentina de años atrás. Ese momento, culmina con Rayuela o, si se quiere, con el Museo de la novela de la Eterna, que se publica en 1967. El objetivo principal de este

Cita sugerida: Menestrina, E. (2017). [Revisión del libro Las tres vanguardias: Saer, Puig, Walsh por Ricardo Piglia]. Orbis Tertius, 22(25), e046. https://doi.org/10.24215/18517811e046 
seminario comprende a la narrativa argentina posterior a Borges. La importancia de cómo se instalan estas poéticas (Saer, Puig y Walsh) serán los puntos de revolución centrales para establecer diálogos con otras poéticas que tienen una relación de continuidad y de corte con uno de los grandes momentos de la literatura nacional. En este sentido, Borges será el punto de referencia para establecer la sincronía y los lazos con otras lenguas y otros autores nacionales. La comparación entre Flaubert y Sarmiento por ser contemporáneos actúa como el fundamento inicial de un debate y revolución dialéctica en la literatura, debido a que, tal como señala Piglia, eran los mejores escritores en sus respectivas lenguas. De esta manera, indica: "el objetivo es definir el concepto de poética de la novela en términos de los debates actuales a partir de los cuales es posible establecer la serie de respuestas narrativas que vamos a considerar: las de Saer, Puig y Walsh” (p. 16).

Asimismo, se abre un debate teórico, en vinculación con los medios de masas, que constituye una perspectiva técnica y un gran aporte a la crítica literaria en un terreno renovador respecto de qué supone construir una novela y la tensión que existe entre arte y entretenimiento. Por lo tanto Saer, Puig y Walsh son las tres respuestas distintas que existen para este problema. Piglia crea una trama de tradiciones en la literatura al discutir el problema de los géneros fuera del ámbito de la literatura nacional. Esta "guerra entre escritores” se encuentra iniciada desde el lugar en el que está definida la propia escritura, observando el espacio donde los textos que se escriben pueden funcionar. Por lo tanto, suponer cómo Saer, Puig y Walsh han construido sus poéticas es el punto de partida desde dichas vanguardias para alcanzar y reconstruir el diálogo con otros autores no nacionales por medio de una red de cuestiones que exceden al ámbito puramente literario. Por este motivo, el artista es un espía en territorio enemigo.

La segunda, tercera y cuarta clase actúan como una apertura del camino literario que se requiere para obtener el desarrollo de estas vanguardias. Para los lectores, la vanguardia debe ser una posición, un lugar o sitio en el campo de la literatura. Su lugar se define por la ruptura con las convenciones establecidas y por su fuerte interés en la experimentación narrativa. Una actitud que excede a la literatura pero la implica en cuanto debates internos entre las poéticas. Y para definir el problema se debe tener en cuenta el enfrentamiento entre los diversos sistemas de lectura, e incluso, cómo el escritor lee la literatura y valora las obras. Para la vanguardia, los juicios de valor son juicios de posición que tienden a la práctica de lectura como una ruptura, desviación o enfrentamiento ante otra posición. La vanguardia, entonces, construye una tradición y destruye otra. En este contexto, la novela se instala como un modo de tradición y traducción en constante tensión con la narración social por medio de la propia experiencia. Por otra parte, la temporalidad y periodización al igual que el problema de cruce de frontera de un género literario con otro, son cuestiones que a Piglia le interesan discutir en profundidad.

En las siguientes seis clases, desde la quinta a la décima inclusive se desarrollan las tres poéticas que componen la estructura central o el núcleo de mayor importancia en este volumen. En el caso de Saer, la estrategia narrativa plantea la fragmentación de la escritura como algo central en el debate narración/novela. Esa tensión atiende al problema de la duración del relato, que es un eje de la construcción en la escritura de este autor. Uno de los mecanismos fundamentales en el proceso escriturario de Saer es el constante movimiento y la acción progresiva en el mundo narrativo. En efecto, los personajes reaparecen y las historias se vuelven a narrar. En Saer, el poeta está siempre escindido y lo más notable es que el autor duplica todo el tiempo. Por esto, los autores tratados, no son vanguardistas porque hayan formado ninguna escuela como André Breton sino que Piglia entiende por escritores de vanguardia, tal como lo concibe Benjamin, a las escrituras que están en constante tensión con problemáticas sociales y con socialización de la poética interna, también. Sus novelas no resisten a la sociedad porque oponen el modelo de la resistencia a la cultura de masas como un marco de manipulación en el que Saer ve la política de Estado como una política de la lengua que se desarrolla a través de un acto revolucionario. 
Igualmente, en el caso de Puig, Piglia explica cómo se desarrolla la técnica de renovación en la novela. La propuesta de este autor radica en crear una novela que comprenda a un público heterogéneo en edad y particular en cuanto al gusto por lo escrito. Su técnica de renovación literaria se inicia cuando introduce material de historias de vida grabadas. Otros mecanismos escriturarios analizados que utiliza Puig son el sistema de interrupción o corte en la escritura en los momentos de mayor tensión y la forma en la que termina sus escritos: un final sin felicidad. De esta manera, la tensión entre arte y vida es constante. En Puig, la ambivalencia surge porque la figura del narrador tiende a ser invisible. En efecto, resulta difícil para Piglia establecer una vinculación entre texto y la parodia cuando no se sabe quién está enunciando. Lo notable de Puig es que logra transformar los materiales crudos en estructuras narrativas con suspenso, desarrollo y enigma muy construidos. Por otro lado, para Piglia, el caso de Walsh es paradigmático ya que en su escritura se desarrolla la tensión entre la vanguardia estética y la vanguardia política, pero lo más interesante es establecer la oscilación entre la escritura de ficción y la de no ficción. En efecto, no existe en Walsh una manipulación como sucedía en Puig. Sin embargo, Piglia establece una relación entre los autores a partir de la tensión entre arte y la vida. Es evidente que la obra de Walsh debe ser pensada y leída en este marco de tensiones internas que giran en torno a cuestiones políticas latentes en ese contexto histórico y social. De esta manera, Piglia propone una gran gama de reflexiones críticas que giran en torno al análisis de diferentes obras en el caso de cada uno de estos autores, los cuales también son objeto de comparación con autores contemporáneos o afines.

Finalmente, en la undécima y última clase, Piglia concluye el seminario con el debate actual sobre la novela y la determinación del corpus. Consecuentemente, establece que dicha determinación requiere de un juicio de valor. En este sentido, la tensión o el debate existente entre los escritores no sólo se ve como una discusión sobre cómo escribir una novela sino que también se discute la problemática de ¿qué es la literatura?, ¿para qué sirve?, ¿qué hacer con ella?, entre otros interrogantes. Si la vanguardia clásica, es la que define la poética de Saer, la histórica la de Walsh y la actual la de Puig, veremos cómo Piglia nos presenta a lo largo de once encuentros tres vanguardias, entendidas como tres momentos de una larga historia; tres autores argentinos puestos en contexto para discutir sus estrategias narrativas y el constante diálogo que ejercen con otros autores no nacionales. Por otra parte, en diferentes intervenciones críticas, Piglia ha defendido la idea del libro híbrido, que incorpora a su vocación combinatoria la voz y la experiencia del autor, como algo que es característico de la literatura contemporánea, e incluso le ha dado a esa presencia un carácter funcional aglutinador de los materiales estéticos y retóricos en las letras nacionales.

Podría decirse, a modo de conclusión, que las clases recogidas en Las tres vanguardias en torno a las poéticas de Saer, Puig y Walsh son la muestra indiscutible de un trabajo riguroso y constante de lectura, de reflexión y análisis por parte de Piglia sobre el lugar del escritor en el mundo de las letras argentinas y sus cosmovisiones poéticas en vinculación con otros autores. Y quizás todavía más, en esos primeros audios y apuntes transcriptos sobre un antiguo cuaderno de notas o en el reverso de hojas ya escritas, sea posible reconocer la marca indeleble, el trazo íntimo y secreto de una pasión que a través de este escrito se conserva con perseverancia y obstinación: la pasión de enseñar y transmitir literatura. 